\title{
Serum Uric Acid Level and Endothelial Dysfunction in Patients with Nondiabetic Chronic Kidney Disease
}

\author{
Mehmet Kanbay ${ }^{a} \quad$ Mahmut Ilker Yilmaz $^{a} \quad$ Alper Sonmez $^{b}$ Faruk Turgut $^{a}$ \\ Mutlu Saglam ${ }^{c}$ Erdinc Cakir ${ }^{d}$ Mujdat Yenicesu ${ }^{a}$ Adrian Covic $^{e}$ Diana Jalal $^{f}$ \\ Richard J. Johnson ${ }^{f}$ \\ Divisions of a Nephrology and ${ }^{b}$ Endocrinology, Department of Medicine, ${ }^{c}$ Department of Radiology and

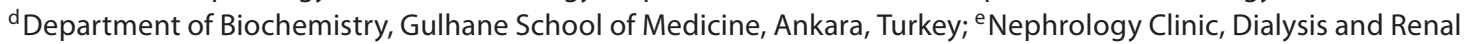 \\ Transplant Center, 'C.I. Parhon' University Hospital, 'Gr. T. Popa' University of Medicine and Pharmacy, lasi, Romania; \\ ${ }^{f}$ Division of Renal Diseases and Hypertension, University of Colorado, Denver, Colo., USA
}

\section{Key Words}

Chronic kidney disease $\cdot$ Uric acid · Endothelial dysfunction

\begin{abstract}
Background: An elevated serum uric acid level is strongly associated with endothelial dysfunction and inflammation, both of which are common in chronic kidney disease (CKD). We hypothesized that endothelial dysfunction in subjects with CKD would correlate with uric acid levels. Materials and Methods: We evaluated the association between serum uric acid level and ultrasonographic flow-mediated dilatation (FMD) in 263 of 486 patients with recently diagnosed CKD (stage 3-5) (48\% male, age $52 \pm 12$ years). To minimize confounding, 233 patients were excluded because they were diabetic, had established cardiovascular complications or were taking drugs (renin-angiotensin system blockers, statins) interfering with vascular function. Results: Serum uric acid level was significantly increased in all stages of CKD and strongly correlated with estimated glomerular filtration rate (eGFR-MDRD); FMD was inversely associated with serum uric acid $(r=-0.49, p<0.001)$. The association of serum uric acid with FMD remained after adjustment for age, gender,
\end{abstract}

smoking, LDL cholesterol, eGFR, high-sensitivity C-reactive protein, systolic blood pressure, proteinuria, and homeostatic model assessment index $(\beta=-0.27, p<0.001)$. Conclusion: Increased serum uric acid is an independent predictor of endothelial dysfunction in subjects with CKD.

Copyright $\odot 2011$ S. Karger AG, Basel

\section{Introduction}

Patients with chronic kidney disease (CKD) often manifest endothelial dysfunction, which is usually defined as a defect in endothelial nitric oxide (NO) bioavailability [1]. At the same time, endothelial dysfunction has emerged as an important risk factor for progression of kidney disease [1]. In the remnant kidney model, an experimental model of CKD, the degree of endothelial dysfunction is an important predictor for progression of kidney disease $[2,3]$. Other studies have also shown that a lack of endothelial NO can accelerate both nondiabetic and diabetic kidney disease as well as aging-related renal disease in laboratory models [4-6].

\section{KARGER}

(C) 2011 S. Karger AG, Basel

Fax +41613061234 E-Mail karger@karger.ch www.karger.com www.karger.com/ajn
Mehmet Kanbay

Alparslan Mahallesi, Umit sokak

No. 25/14, Melikgazi

TR-38030 Kayseri (Turkey)

Tel. +90 50526688 66, E-Mail drkanbay@yahoo.com 
Fig. 1. Flow diagram of the study popula-

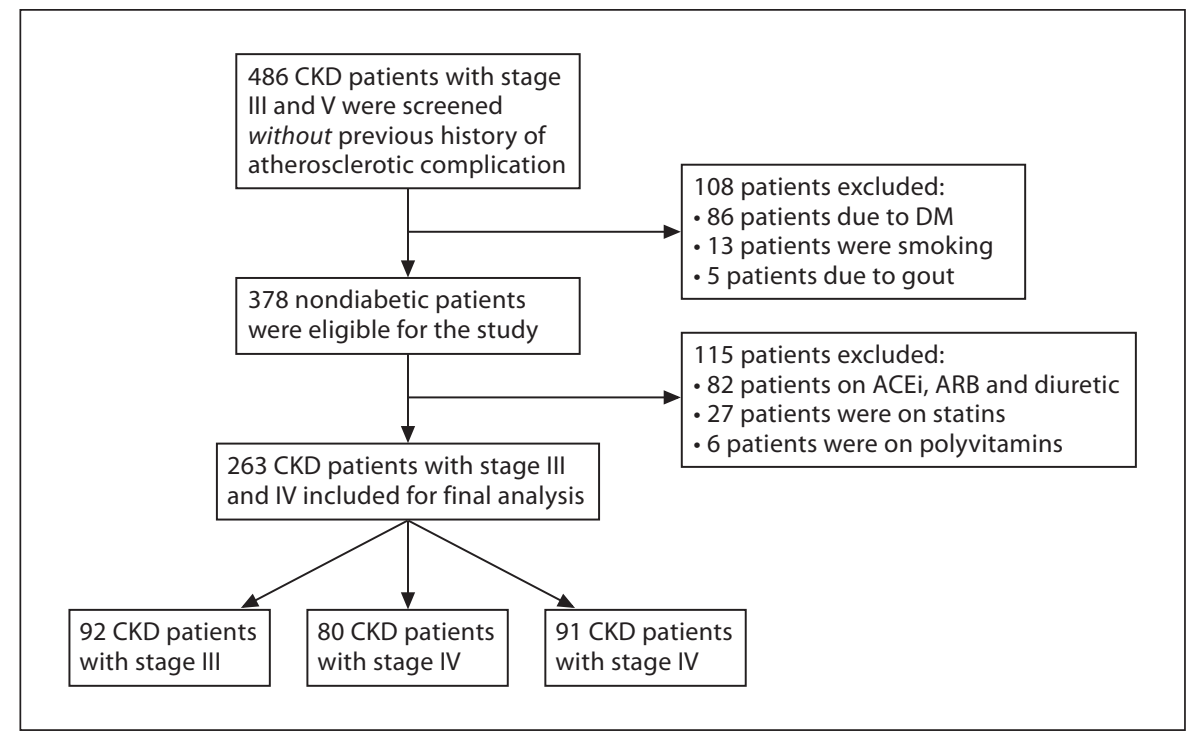
tion.

Endothelial function, as determined by the dilation of the brachial artery following transient occlusion (flowmediated dilation (FMD)), is inversely correlated with serum uric acid levels in subjects with asymptomatic hyperuricemia as well as in hyperuricemia associated with essential hypertension [7-9]. Uric acid has also been found to reduce NO in cultured endothelial cells, probably by inducing intracellular oxidative stress and inflammation [10-13]. Conversely, reducing uric acid with a xanthine oxidase inhibitor improves endothelial function in subjects with asymptomatic hyperuricemia as well as in association with a wide variety of conditions, including diabetes, heart failure, or sleep apnea syndrome [9, 14-18]. Nevertheless, no study has examined the relationship between uric acid and endothelial function in subjects with CKD. This is important as it is recognized that CKD may be associated with other conditions that potentially reduce endothelial function, including oxidative stress and circulating NO synthase inhibitors [1, 1921]. We therefore tested the hypothesis that serum uric acid is an independent predictor of endothelial dysfunction in subjects with nondiabetic CKD.

\section{Materials and Methods}

\section{Study Population}

The Ethical Committee of Gulhane School of Medicine (EtlikAnkara, Turkey) approved the study, and all patients gave their informed consent. Between May 2005 and May 2010, a total number of 486 patients with CKD stage 3-5 were referred to the nephrology outpatient clinics of Gulhane School of Medicine be- cause of suspected or manifest renal failure. Part of the patient population was included in previous analyses carried out on the same endothelial-function studies database $[22,23]$.

All patients received for the first time a diagnosis of CKD according to their estimated glomerular filtration rate (eGFR) and the presence of kidney injury as defined by National Kidney Foundation Kidney Disease Outcomes Quality Initiative (K/DQOI) guidelines calculated according to the simplified version of the Modification of Diet in Renal Disease (MDRD) formula as defined by Levey et al. [24] and were classified with respect to eGFR levels from stages 3 to 5 . To diminish any confounders that may influence patients with endothelial dysfunction, patients with established atherosclerotic complication (coronary artery disease, congestive heart failure, or peripheral vascular disease), on dialysis and nephrotic syndrome were not included. We also excluded subjects with a history of smoking, or current use of angiotensin-converting enzyme inhibitors, angiotensin receptor blockers, statins, and supplemental vitamins/polyvitamins including folic acid and vitamin $B_{12}$. In addition, patients with a previous diagnosis of gout, diabetes, current use of oral antidiabetic medication, insulin, thiazide, allopurinol or uricosuric, or a fasting glucose level 126 $\mathrm{mg} / \mathrm{dl}$ were excluded. Finally, an unwillingness to participate in the study also qualified for exclusion (fig. 1).

378 nondiabetic patients were eligible for the study. 82 patients were excluded because they were on treatment with angiotensinconverting enzyme (ACE) inhibitors or angiotensin receptor blockers, 27 because they were on statins, and 6 because they were being treated with polyvitamins. None of the patients were being treated with erythropoietin-stimulating agents (ESA). Thus, 263 nondiabetic patients were eventually selected. 92 patients had stage $3 \mathrm{CKD}, 80$ stage $4 \mathrm{CKD}$, and 91 stage $5 \mathrm{CKD}$. None had acute infections at the time of the study. The etiology of CKD in these patients was chronic glomerulonephritis in 46, nephrosclerosis in 67 , chronic pyelonephritis in 23 , reflux nephropathy in 19 , autosomal polycystic kidney disease in 26 , and unknown in 82 . At the time of the study, 26 patients were taking calcium channel blockers, $4 \beta$-blockers and 5 diuretics. 


\section{Blood Pressure Measurements}

Hypertension was defined as systolic blood pressure (SBP) $>140 \mathrm{~mm} \mathrm{Hg}$ or diastolic BP (DBP) $>90 \mathrm{~mm} \mathrm{Hg}$ on repeated measurements or the use of antihypertensive drugs. The arterial BPs were measured by a physician three times after a 15 -min resting period in the morning, and mean values were calculated for SBP and DBP for all participants.

\section{Laboratory Measurements}

Blood sampling was performed in the morning, after $12 \mathrm{~h}$ of fasting. Samples $(6-8 \mathrm{ml})$ of venous blood were collected from each subject in the morning between 08:00 and 09:00, after an overnight fast. After clot formation, the samples were centrifuged $(4,000 \mathrm{rpm})$ at room temperature for $10 \mathrm{~min}$. The serum samples were stored at $-80^{\circ} \mathrm{C}$ until the time of the assay.

In all patients we measured fasting plasma glucose, total serum cholesterol, triglyceride, high-density lipoprotein, low-density lipoprotein (LDL) cholesterol. 24-hour urine collection was performed three times and the average of three 24 -hour proteinuria measurements was taken as representative of each participant's 24-hour protein excretion rate.

The basal insulin level was measured by the coated tube method (DPC, USA). An insulin resistance score homeostasis model assessment-insulin resistance (HOMA-IR) was computed which was previously defined [25]. Measurements of high-sensitivity Creactive protein (hsCRP) were done according to well-established methods which we have described in detail elsewhere [26].

Serum uric acid levels were determined in all samples. All assays were performed in the central laboratory of the Gulhane Military Medical Academy Hospital, with an Olympus AU2700 autoanalyzer using its own kits (Olympus Diagnostics, Hamburg, Germany).

\section{Vascular Assessment}

According to the method of Celermajer et al. [27], the endothelium-dependent vasodilation (FMD) of the brachial artery were assessed by using high-resolution ultrasound. Measurements were made by a single observer using an ATL 5000 ultrasound system (Advanced Technology Laboratories, Bothell, Wash., USA) with a $12-\mathrm{MHz}$ probe. All vasoactive medications were withheld for $24 \mathrm{~h}$ before the procedure. The subjects remained at rest in the supine position for at least $15 \mathrm{~min}$ before the examination started. The participant's arm was comfortably immobilized in the extended position to allow consistent recording of the brachial artery $2-4 \mathrm{~cm}$ above the antecubital fossa. Three adjacent measurements of end-diastolic brachial artery diameter were made from single two-dimensional frames. All ultrasound images were recorded on S-VHS videotape for subsequent blinded analysis. A pneumatic tourniquet was inflated to $200 \mathrm{~mm} \mathrm{Hg}$ with obliteration of the radial pulse. After $5 \mathrm{~min}$, the cuff was deflated. Flow measurements were made $60 \mathrm{~s}$ after deflation. The maximum FMD dilation diameters were calculated as the average of the three consecutive maximum diameter measurements. The FMD was then calculated as the percentage change in diameter compared with baseline resting diameters.

\section{Statistical Analysis}

All data are presented as mean \pm SD unless stated otherwise. Continuous variables were checked for the normal distribution assumption using the Kolmogorov-Smirnov statistics and those that did not satisfy the criteria were log-transformed to attain normal distribution. The study group was divided in two subgroups based on the median serum uric acid level. Differences among the groups were analyzed by Student's t test (continuous variables) and the $\chi^{2}$ test (categorical variables). All potential (physiologically meaningful) determinants of the serum uric acid were investigated in a univariate screening procedure, using Pearson's coefficient of correlation test. The nonparametric Spearman $\rho$ coefficient of correlation was used to assess correlations between variables without normal distribution. Finally, multiple regression analysis was applied to test the independent link between FMD and potential functional correlates of this variable. To this scope we computed models of increasing complexity adjusting for traditional (Framingham risk factors) and emerging risk factors as well as for the diagnosis of renal disease and inflammatory parameters. $\mathrm{p}<0.05$ for the final model was considered as statistically significant. Data were analyzed using the SSPS 15.0 for Windows software (SPSS Inc., Chicago, Ill., USA).

\section{Results}

The demographic, clinical, and biochemical characteristics of the study population, categorized according to the median serum uric acid value $(7.5 \mathrm{mg} / \mathrm{dl})$, are shown in table 1 .

\section{Categorical Analysis of Uric Acid and Other Risk \\ Factors}

No significant differences were found between subjects with serum uric acid above the median and those below the median with regard to age, gender, body mass index, DBP, serum albumin, LDL cholesterol, HOMA index, and proteinuria $(p>0.05)$. Subjects with higher serum uric acid levels had a higher SBP $(p=0.007)$, higher CRP levels $(\mathrm{p}<0.001)$ and lower eGFR $(\mathrm{p}<0.001)$. Using categorical analysis, FMD was significantly less in subjects with higher serum uric acid (defined as above the median value, $\mathrm{p}<0.001)$.

\section{Uni- and Multivariate Analyses}

Uric acid was closely associated with FMD $(\mathrm{r}=-0.49$, $\mathrm{p}<0.001$; fig. 2), eGFR ( $\mathrm{r}=-0.47, \mathrm{p}<0.001)$, and hsCRP $(r=0.24, p<0.001)$, but not with age, gender, SBP and DBP, LDL cholesterol and proteinuria. On the other hand, FMD correlated inversely with uric acid $(\mathrm{r}=-0.49, \mathrm{p}<$ 0.001), eGFR ( $\mathrm{r}=0.59, \mathrm{p}<0.001)$, hsCRP $(\mathrm{r}=-0.33$, $\mathrm{p}<$ $0.001)$, SBP $(r=-0.20, p=0.001)$ and serum albumin $(r=$ $0.31, \mathrm{p}<0.001)$.

To determine the independent contribution of uric acid to FMD, we constructed a series of multiple regression models based on traditional and nontraditional risk 
Table 1. Demographics and biochemical data of the nondiabetic CKD patients categorized according to median serum uric acid level $(7.5 \mathrm{mg} / \mathrm{dl})$

\begin{tabular}{|c|c|c|c|c|}
\hline Parameters & $\begin{array}{l}\text { CKD patients } \\
(\mathrm{n}=263)\end{array}$ & $\begin{array}{l}\text { Uric acid }<7.5 \mathrm{mg} / \mathrm{dl} \\
(\mathrm{n}=132)\end{array}$ & $\begin{array}{l}\text { Uric acid } \geq 7.5 \mathrm{mg} / \mathrm{dl} \\
(\mathrm{n}=131)\end{array}$ & $\mathrm{p}$ value \\
\hline Age, years & $52 \pm 12$ & $50.7 \pm 11.3$ & $53.2 \pm 13$ & 0.06 \\
\hline Male gender, n (\%) & $126(48)$ & $66(50)$ & $60(46)$ & 0.49 \\
\hline BMI & $25.9 \pm 2.7$ & $26 \pm 2.4$ & $25.7 \pm 3.1$ & 0.61 \\
\hline $\mathrm{SBP}, \mathrm{mm} \mathrm{Hg}$ & $134 \pm 11$ & $132 \pm 11$ & $135 \pm 10$ & 0.007 \\
\hline DBP, mm Hg & $85 \pm 5$ & $84 \pm 5$ & $84 \pm 4$ & 0.56 \\
\hline $\mathrm{eGFR}, \mathrm{ml} / \mathrm{min} / 1.73 \mathrm{~m}^{2}$ & $26 \pm 16.6$ & $33.1 \pm 15.7$ & $18.8 \pm 14.3$ & $<0.0001$ \\
\hline Proteinuria, mg/24 h & $1,925 \pm 1,103$ & $1,958 \pm 1,075$ & $1,892 \pm 1,134$ & 0.16 \\
\hline HOMA index & $1.8 \pm 0.9$ & $1.8 \pm 1$ & $1.8 \pm 0.8$ & 0.14 \\
\hline $\mathrm{CRP}, \mathrm{mg} / \mathrm{dl}$ & $20.5 \pm 7.3$ & $18.5 \pm 6.7$ & $22.4 \pm 7.4$ & $<0.0001$ \\
\hline LDL cholesterol, mg/dl & $125.7 \pm 17.1$ & $126 \pm 17$ & $125.3 \pm 17.3$ & 0.66 \\
\hline $\mathrm{FMD}, \%$ & $6.4 \pm 0.9$ & $6.8 \pm 0.8$ & $5.9 \pm 0.9$ & $<0.0001$ \\
\hline
\end{tabular}

Values are means \pm SD unless otherwise indicated. Bold values indicate the significant values $(\mathrm{p}<0.05)$.

Table 2. Multiple regression models of FMD in patients with CKD stages 3 and 4

\begin{tabular}{|c|c|c|c|c|c|c|c|c|}
\hline & \multicolumn{2}{|c|}{ Unadjusted } & \multicolumn{2}{|c|}{ Model $1\left(r^{2}=0.27\right)$} & \multicolumn{2}{|c|}{ Model $2\left(r^{2}=0.43\right)$} & \multicolumn{2}{|c|}{ Model $3\left(r^{2}=0.43\right)$} \\
\hline & $\bar{\beta}$ & $\mathrm{p}$ & $\bar{\beta}$ & $\mathrm{p}$ & $\bar{\beta}$ & $\mathrm{p}$ & $\bar{\beta}$ & $\mathrm{p}$ \\
\hline Uric acid, mg/dl & -0.49 & $<0.001$ & -0.48 & $<0.001$ & -0.27 & $<0.001$ & -0.27 & $<0.001$ \\
\hline Age & & & 0.04 & 0.45 & 0.03 & 0.47 & 0.02 & 0.60 \\
\hline Gender & & & 0.08 & 0.11 & 0.08 & 0.09 & 0.08 & 0.08 \\
\hline SBP & & & -0.14 & 0.009 & -0.11 & 0.03 & -0.06 & 0.09 \\
\hline LDL cholesterol & & & -0.007 & 0.89 & -0.02 & 0.64 & -0.02 & 0.56 \\
\hline Smoking & & & 0.03 & 0.56 & 0.02 & 0.59 & 0.02 & 0.64 \\
\hline BMI & & & -0.02 & 0.71 & -0.01 & 0.79 & -0.01 & 0.71 \\
\hline GFR & & & & & 0.45 & $<0.001$ & 0.41 & $<0.001$ \\
\hline Proteinuria & & & & & 0.03 & 0.95 & 0.001 & 0.98 \\
\hline $\mathrm{CRP}, \mathrm{mg} / \mathrm{dl}$ & & & & & & & -0.08 & 0.11 \\
\hline HOMA & & & & & & & -0.09 & 0.06 \\
\hline
\end{tabular}

Bold values indicate the significant values $(\mathrm{p}<0.05)$.

factors impacting upon FMD. All the parameters that significantly correlated with FMD, as well as other factors considered physiologically as potentially relevant for FMD, were introduced in standard multivariate regression analysis in a three-step procedure, using the enter method. In the first step we evaluated the independent influence of uric acid and Framingham risk factors on FMD in our population. In this first step, uric acid $(\beta=$ $-0.48, \mathrm{p}<0.001)$, FGF-23 $(\beta=0.47, \mathrm{p}=0.001)$ and SBP $(\beta=-0.14, p=0.009)$ were the only statistically signifi- cant independent predictors that correlated with FMD (table 2).

In the second step, we adjusted for the presence of Framingham risk factors, proteinuria and eGFR. After these adjustments, serum uric acid $(\beta=-0.27, p<0.001)$, $\operatorname{SBP}(\beta=-0.11, \mathrm{p}=0.03)$, and eGFR $(\beta=0.45, \mathrm{p}<0.001)$ remained statistically significant predictors of the FMD (table 2).

In the third step, we adjusted for the presence of Framingham risk factors, proteinuria, eGFR, HOMA and 


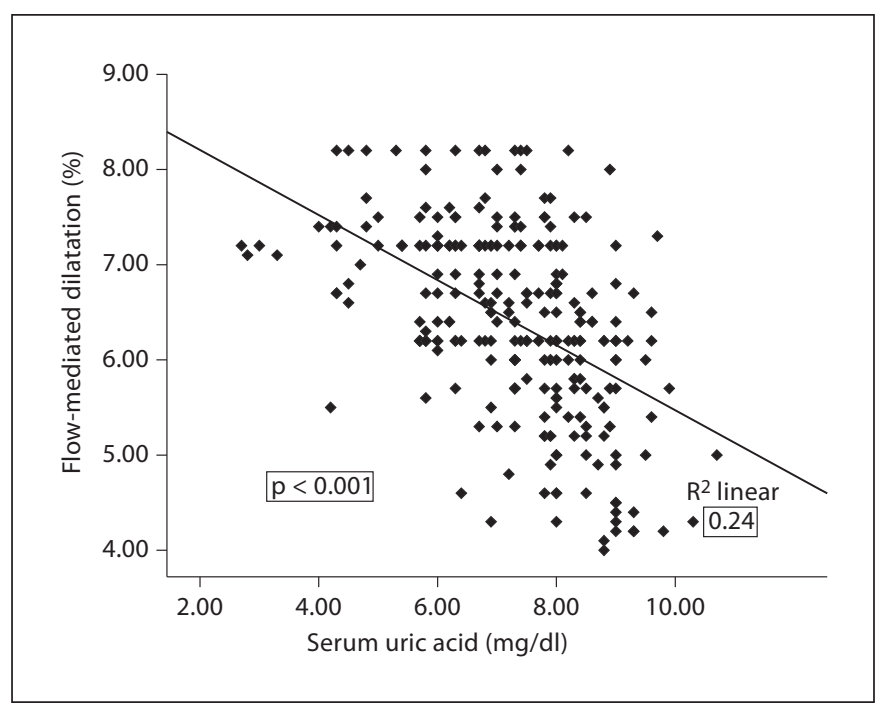

Fig. 2. Correlation between FMD and uric acid in patients with CKD stage 3-5.

hsCRP. After these adjustment, only uric acid $(\beta=-0.27$, $p<0.001)$ and eGFR $(\beta=0.41, p<0.001)$ remained significant predictors of FMD.

We also performed an analysis in which subjects with elevated serum uric acid levels (defined as $\geq 7 \mathrm{mg} / \mathrm{dl}$ in men and $\geq 6 \mathrm{mg} / \mathrm{dl}$ in women) were excluded in order to determine if uric acid levels within the normal range also predicted FMD. Of the 263 subjects, 70 had normal uric acid levels. When this group was divided into two groups according to the median values, FMD remained significantly less in subjects with the higher serum uric acid (defined as above the median value, $\mathrm{p}=0.03$ ).

\section{Discussion}

The primary finding in this study was that endothelial dysfunction, as determined by measuring FMD, was independently associated with both reduced eGFR and with elevations in serum uric acid levels. Specifically, we evaluated endothelial function in 263 nondiabetic subjects with CKD and a mean eGFR of $26 \mathrm{ml} / \mathrm{min} / 1.73 \mathrm{~m}^{2}$. In this group, the median serum uric acid was $7.5 \mathrm{mg} / \mathrm{dl}$. FMD varied markedly, with a range from 4 to $8.2 \%$ (mean $6.4 \%)$. Importantly, endothelial function correlated inversely with serum uric acid levels (fig. 2). Multivariate analysis confirmed that uric acid was an important predictor of endothelial function, independent of numerous risk factors including eGFR and the Framingham risk factors. These studies suggest that uric acid could have a role in driving endothelial dysfunction in subjects with nondiabetic CKD. Since endothelial dysfunction appears to be a major risk factor for progression of CKD [1], our data provide a rationale for lowering uric acid in CKD, as a means to slow renal disease progression.

There is already consistent evidence that uric acid may have a role in the progression of CKD. For example, several studies have shown that an elevated uric acid predicts the development of CKD in the general population [2830]. An elevated uric acid also predicts the development of diabetic nephropathy in subjects with type 1 diabetes $[31,32]$. Experimental studies have reported that lowering uric acid can slow renal disease progression in both diabetic and nondiabetic renal disease [33, 34]. Furthermore, several pilot studies suggest that lowering uric acid with a xanthine oxidase inhibitor can improve renal function in subjects without $\mathrm{CKD}$, and may slow renal progression in subjects with CKD [35-37]. In this regard, Goicoechea et al. [37] recently reported a randomized trial in which allopurinol (100 mg/day) slowed renal progression and reduced cardiovascular events in subjects with stage 3 CKD.

In this analysis, we excluded subjects receiving ACE inhibitors or statins as they are known to influence endothelial function and hence could be confounders.

We were most interested in the role of reduced eGFR itself, as this may lead to retention of substances such as uric acid and asymmetric dimethylarginine, the latter considered a circulating uremic toxin that competes with L-arginine for endothelial NO synthase $[19,20]$. Importantly, both eGFR and uric acid emerged as independent risk factors for endothelial dysfunction. This suggests that uric acid might affect endothelial function distinct from the effects of reduced GFR, and hence may provide a new therapeutic target to reduce renal disease progression.

It is important to recognize that the independent association of uric acid with endothelial function in this study does not imply that uric acid is directly responsible for the endothelial dysfunction. Indeed, uric acid could reflect underling xanthine oxidase activity, since xanthine oxidase generates uric acid from xanthine. In addition, xanthine oxidase is also known to generate oxidants. In this way, an elevated uric acid could simply reflect the presence of xanthine oxidase-associated oxidants, which may be ultimately responsible for the endothelial dysfunction [38]. Indeed, George et al. [38] reported that endothelial function in subjects with congestive heart fail- 
ure improved only when uric acid was lowered by a xanthine oxidase inhibitor as opposed to when a uricosuric was utilized. Waring et al. [39] also suggested that the acute infusion of uric acid actually improves endothelial function rather than impairs it, in subjects with diabetes. However, while uric acid in the extracellular environment is an antioxidant, there is increasing evidence that uric acid, when entering the cells, is prooxidative and directly induces endothelial dysfunction [10-13, 40,41]. Allopurinol may improve endothelial function better than uricosurics by reducing intracellular uric acid more effectively.

In conclusion, subjects with nondiabetic CKD display a wide range of endothelial function, as measured by FMD. Subjects with a higher uric acid $(>7.5 \mathrm{mg} / \mathrm{dl})$ have a significantly worse FMD compared to subjects with uric acid levels $<7.5 \mathrm{mg} / \mathrm{dl}$. This relationship persists after controlling for all Framingham risk factors and eGFR.
Since endothelial function is an important risk factor for renal progression, this study suggests the importance of determining if lowering uric acid can improve endothelial function in CKD and whether this can translate into significant slowing or improvement in renal function.

\section{Acknowledgement}

R.J.J. is supported by NIH grant HL-68607.

\section{Disclosure Statement}

R.J.J. has patent applications related to lowering uric acid as a means to treat hypertension, reduce the frequency of diabetes, and treat fatty liver. The other authors have no relationships or financial interests with companies related to the findings of this work. There are no conflicts of interest to disclose.

\section{References}

1 Baylis C: Nitric oxide deficiency in chronic kidney disease. Am J Physiol 2008;294:F1F9.

-2 Gschwend S, Buikema H, Navis G, Henning RH, de Zeeuw D, van Dokkum RP: Endothelial dilatory function predicts individual susceptibility to renal damage in the 5/6 nephrectomized rat. J Am Soc Nephrol 2002; 13:2909-2915.

-3 Ochodnicky P, Vettoretti S, Henning RH, Buikema H, Van Dokkum RP, de Zeeuw D: Endothelial dysfunction in chronic kidney disease: determinant of susceptibility to end-organ damage and therapeutic response. J Nephrol 2006;19:246-258.

4 Nakagawa T, Sato W, Glushakova O, Heinig M, Clarke T, Campbell-Thompson M, Yuzawa Y, Atkinson MA, Johnson RJ, Croker B: Diabetic endothelial nitric oxide synthase knockout mice develop advanced diabetic nephropathy. J Am Soc Nephrol 2007; 18: 539-550.

$\checkmark 5$ Nakayama T, Sato W, Kosugi T, Zhang L, Campbell-Thompson M, Yoshimura A, Croker BP, Johnson RJ, Nakagawa T: Endothelial injury due to eNOS deficiency accelerates the progression of chronic renal disease in the mouse. Am J Physiol 2009;296:F317-F327.

-6 Nakayama T, Sato W, Yoshimura A, Zhang L, Kosugi T, Campbell-Thompson M, Kojima H, Croker BP, Nakagawa T: Endothelial von Willebrand factor release due to eNOS deficiency predisposes to thrombotic microangiopathy in mouse aging kidney. Am J Pathol 2010;176:2198-2208.
7 Erdogan D, Gullu H, Caliskan M, Yildirim E, Bilgi M, Ulus T, Sezgin N, Muderrisoglu H: Relationship of serum uric acid to measures of endothelial function and atherosclerosis in healthy adults. Int J Clin Pract 2005;59: 1276-1282.

8 Zoccali C, Maio R, Mallamaci F, Sesti G, Perticone F: Uric acid and endothelial dysfunction in essential hypertension. J Am Soc Nephrol 2006; 17:1466-1471.

-9 Mercuro G, Vitale C, Cerquetani E, Zoncu S, Deidda M, Fini M, Rosano GM: Effect of hyperuricemia upon endothelial function in patients at increased cardiovascular risk. Am J Cardiol 2004;94:932-935

10 Khosla UM, Zharikov S, Finch JL, Nakagawa T, Roncal C, Mu W, Krotova K, Block ER, Prabhakar S, Johnson RJ: Hyperuricemia induces endothelial dysfunction. Kidney Int 2005;67:1739-1742.

-11 Zharikov S, Krotova K, Hu H, Baylis C, Johnson RJ, Block ER, Patel J: Uric acid decreases no production and increases arginase activity in cultured pulmonary artery endothelial cells. Am J Physiol Cell Physiol 2008; 295:C1183-C1190.

12 Kang DH, Park SK, Lee IK, Johnson RJ: Uric acid-induced C-reactive protein expression: implication on cell proliferation and nitric oxide production of human vascular cells. J Am Soc Nephrol 2005;16:3553-3562.

13 Yu MA, Sanchez-Lozada LG, Johnson RJ, Kang DH: Uric acid: an inducer of oxidative stress and renin-angiotensin system in human vascular endothelial cells. J Hypertens 2010;28:1234-1242.
14 Butler R, Morris AD, Belch JJ, Hill A, Struthers AD: Allopurinol normalizes endothelial dysfunction in type 2 diabetics with mild hypertension. Hypertension 2000;35: 746-751.

15 Doehner W, Schoene N, Rauchhaus M, Leyva-Leon F, Pavitt DV, Reaveley DA, Schuler G, Coats AJ, Anker SD, Hambrecht R: Effects of xanthine oxidase inhibition with allopurinol on endothelial function and peripheral blood flow in hyperuricemic patients with chronic heart failure: results from two placebo-controlled studies. Circulation 2002;105: 2619-2624.

-16 Farquharson CA, Butler R, Hill A, Belch JJ, Struthers AD: Allopurinol improves endothelial dysfunction in chronic heart failure. Circulation 2002;106:221-226.

17 Guthikonda S, Sinkey C, Barenz T, Haynes WG: Xanthine oxidase inhibition reverses endothelial dysfunction in heavy smokers. Circulation 2003;107:416-421.

-18 El Solh AA, Saliba R, Bosinski T, Grant BJ, Berbary E, Miller N: Allopurinol improves endothelial function in sleep apnoea: a randomised controlled study. Eur Respir J 2006; 27:997-1002.

19 Vallance P, Leone A, Calver A, Collier J, Moncada S: Accumulation of an endogenous inhibitor of nitric oxide synthesis in chronic renal failure. Lancet 1992;339:572-575.

20 Baylis C: Arginine, arginine analogs and nitric oxide production in chronic kidney disease. Nat Clin Pract Nephrol 2006;2:209220. 
-21 Xiao S, Schmidt RJ, Baylis C: Plasma from ESRD patients inhibits nitric oxide synthase activity in cultured human and bovine endothelial cells. Acta Physiol Scand 2000;168: 175-179.

-22 Yilmaz MI, Carrero JJ, Ortiz A, Martin-Ventura JL, Sonmez A, Saglam M, Yaman H, Yenicesu M, Egido J, Blanco-Colio LM: Soluble tweak plasma levels as a novel biomarker of endothelial function in patients with chronic kidney disease. Clin J Am Soc Nephrol 2009; 4:1716-1723.

-23 Yilmaz MI, Sonmez A, Saglam M, Yaman H, Kilic S, Demirkaya E, Eyileten T, Caglar K, Oguz Y, Vural A, Yenicesu M, Zoccali C: FGF-23 and vascular dysfunction in patients with stage 3 and 4 chronic kidney disease. Kidney Int 2010;78:679-685.

24 Levey AS, Bosch JP, Lewis JB, Greene T, Rogers N, Roth D: A more accurate method to estimate glomerular filtration rate from serum creatinine: a new prediction equation. Modification of Diet in Renal Disease Study Group. Ann Intern Med 1999;130:461-470.

-25 Matthews DR, Hosker JP, Rudenski AS, Naylor BA, Treacher DF, Turner RC: Homeostasis model assessment: insulin resistance and $\beta$-cell function from fasting plasma glucose and insulin concentrations in man. Diabetologia 1985;28:412-419.

-26 Yilmaz MI, Saglam M, Caglar K, Cakir E, Sonmez A, Ozgurtas T, Aydin A, Eyileten T, Ozcan O, Acikel C, Tasar M, Genctoy G, Erbil K, Vural A, Zoccali C: The determinants of endothelial dysfunction in CKD: oxidative stress and asymmetric dimethylarginine. Am J Kidney Dis 2006;47:42-50.
27 Celermajer DS, Sorensen KE, Gooch VM, Spiegelhalter DJ, Miller OI, Sullivan ID, Lloyd JK, Deanfield JE: Non-invasive detection of endothelial dysfunction in children and adults at risk of atherosclerosis. Lancet 1992;340:1111-1115.

28 Weiner DE, Tighiouart H, Elsayed EF, Griffith JL, Salem DN, Levey AS: Uric acid and incident kidney disease in the community. J Am Soc Nephrol 2008;19:1204-1211.

29 Iseki K, Ikemiya Y, Inoue T, Iseki C, Kinjo K, Takishita S: Significance of hyperuricemia as a risk factor for developing ESRD in a screened cohort. Am J Kidney Dis 2004;44: $642-650$.

-30 Obermayr RP, Temml C, Gutjahr G, Knechtelsdorfer M, Oberbauer R, Klauser-Braun R Elevated uric acid increases the risk for kidney disease. J Am Soc Nephrol 2008;19: 2407-2413.

31 Hovind P, Rossing P, Tarnow L, Johnson RJ, Parving $\mathrm{HH}$ : Serum uric acid as a predictor for development of diabetic nephropathy in type 1 diabetes: an inception cohort study. Diabetes 2009;58:1668-1671.

-32 Jalal DI, Rivard CJ, Johnson RJ, Maahs DM, McFann K, Rewers M, Snell-Bergeon JK: Serum uric acid levels predict the development of albuminuria over 6 years in patients with type 1 diabetes: findings from the coronary artery calcification in type 1 diabetes study. Nephrol Dial Transplant 2010;25:1865-1869.

33 Kosugi T, Nakayama T, Heinig M, Zhang L, Yuzawa Y, Sanchez-Lozada LG, Roncal C, Johnson RJ, Nakagawa T: Effect of lowering uric acid on renal disease in the type 2 diabetic db/db mice. Am J Physiol 2009;297: F481-F488.

>34 Kang DH, Nakagawa T, Feng L, Watanabe S, Han L, Mazzali M, Truong L, Harris R, Johnson RJ: A role for uric acid in the progression of renal disease. J Am Soc Nephrol 2002;13: 2888-2897.
35 Kanbay M, Ozkara A, Selcoki Y, Isik B, Turgut F, Bavbek N, Uz E, Akcay A, Yigitoglu R, Covic A: Effect of treatment of hyperuricemia with allopurinol on blood pressure, creatinine clearance, and proteinuria in patients with normal renal functions. Int Urol Nephrol 2007;39:1227-1233.

36 Siu YP, Leung KT, Tong MK, Kwan TH: Use of allopurinol in slowing the progression of renal disease through its ability to lower serum uric acid level. Am J Kidney Dis 2006; 47:51-59.

>37 Goicoechea M, de Vinuesa SG, Verdalles U, Ruiz-Caro C, Ampuero J, Rincon A, Arroyo D, Luno J: Effect of allopurinol in chronic kidney disease progression and cardiovascular risk. Clin J Am Soc Nephrol 2010;5:13881393.

>38 George J, Carr E, Davies J, Belch JJ, Struthers A: High-dose allopurinol improves endothelial function by profoundly reducing vascular oxidative stress and not by lowering uric acid. Circulation 2006;114:2508-2516.

39 Waring WS, McKnight JA, Webb DJ, Maxwell SR: Uric acid restores endothelial function in patients with type 1 diabetes and regular smokers. Diabetes 2006;55:3127-3132.

40 Sanchez-Lozada LG, Soto V, Tapia E, AvilaCasado C, Sautin YY, Nakagawa T, Franco M, Rodriguez-Iturbe B, Johnson RJ: Role of oxidative stress in the renal abnormalities induced by experimental hyperuricemia. Am J Physiol 2008;295:F1134-F1141.

41 Sanchez-Lozada LG, Tapia E, Lopez-Molina R, Nepomuceno T, Soto V, Avila-Casado C, Nakagawa T, Johnson RJ, Herrera-Acosta J, Franco M: Effects of acute and chronic L-arginine treatment in experimental hyperuricemia. Am J Physiol 2007;292:F1238-F1244. 